\title{
Current Safety Standards in Infant Nutrition - A European Perspective
}

\author{
Olle Hernell \\ Pediatrics, Department of Clinical Sciences, Umeå University, Umeå, Sweden
}

\section{Key Words}

Infant formula $\cdot$ Baby food $\cdot$ Food safety $\cdot$ Nutrition

\begin{abstract}
Foods intended specifically for infants and young children are considered under European community law and are defined in specific commission directives. In principal, these directives conclude that such foods must be safe, have a special composition, be distinguishable from normal foods, be suitable for fulfilling particular nutritional requirements, and should, when marketed, indicate such suitability. Since infant formulas are intended as the sole source of nutrition during the first months of life, their nutritional adequacy and safety are particularly strictly regulated. The Scientific Committee on Food report from 2003, on which the current commission directive is based, makes clear recommendations on how benefits, suitability, and safety of modifications beyond established standards should be documented and evaluated. These principles resulted in part from a workshop on characterization of infant food modifications in the EU and two position papers by the European Society for Pediatric Gastroenterology, Hepatology and Nutrition (ESPGHAN). These papers are reviewed below.
\end{abstract}

Copyright $\odot 2012$ S. Karger AG, Basel
The legal framework for infant and baby foods was reviewed in a workshop held in June 2002 sponsored by The Child Health Foundation (Munich) and the European Society for Pediatric Gastroenterology, Hepatology and Nutrition (ESPGHAN) with presence of academia, infant food industry, consumer organizations, the Health and Consumer Protection Directorate General of the European Commission, and food regulatory bodies of some EU member states. The background was based on the current situation that in Europe new ingredients could be added to infant formulas and follow-on formulas if their suitability for particular use by infants from birth had been established by generally accepted scientific data for infants. Uncertainty was felt if the required evaluation of modifications in dietetic products for infants could be regarded as suitable and safe. The workshop addressed the following questions: What nature of evidence is needed to characterize suitability and safety of infant formulas, follow-on formulas, and other dietetic products? Is a reasonable indication of a functional, clinical, and other benefit required to justify formula modification, or is documentation of reasonable safety sufficient without indication of benefit? Which approaches might be suitable to appropriately characterize product properties that might be communicated? [1].

\section{KARGER \\ Fax +4161306 1234 \\ E-Mail karger@karger.ch}

www.karger.com
(C) 2012 S. Karger AG, Basel

0250-6807/12/0603-0188\$38.00/0

Accessible online at:

www.karger.com/anm
Olle Hernell

Pediatrics, Department of Clinical Sciences

Umeå University

SE-90185 Umeå (Sweden)

Tel. +4690785 2121, E-Mail olle.hernell@ pediatri.umu.se 


\section{Legal Framework for Infant and Baby Foods in Europe}

Foods intended specifically for infants and young children are considered under European community law as foods for particular nutritional uses (dietetic foods) defined in a commission directive [2]. They must be safe, have a special composition, be distinguishable from normal foods, be suitable for fulfilling particular nutritional requirements, and should, when marketed, indicate such suitability. Dietetic foods for infants and young children in good health are regulated by several specific or vertical directives which lay down necessary definitions, detailed compositional criteria, and specific labeling requirements, including certain conditions for claims. The basic composition is strictly defined in EU directives on infant formulas and follow-on formulas from 2006 [3], based on the preceding Scientific Committee on Food (SCF) report from 2003 [4], processed cereal-based foods and baby foods for infants and young children from 2006 [5], and dietary foods for special medical purposes from 1999 [6]. Moreover, there should be compliance with a number of horizontal regulations and several additional directives. Further, there is a EU white paper on food safety stating that: 'Consumers have the right to expect information on food quality and constituents that are helpful and clearly presented so that informed choices can be made' [7].

\section{The Nutritional and Safety Assessment of Breast Milk Substitutes}

It was noted that the issue of assessment of safety of breast milk substitutes had been addressed in a position paper by the Committee of Nutrition (CoN) of ESPGHAN the previous year [8], which pointed out the need to review the evaluation of infant formulas and breast milk substitutes, focusing also on longer-term nutritional and safety outcomes, something that had until then been largely neglected. The paper highlighted the need of systematic evaluation of nutritional and safety characteristics of dietary products for use in infants (e.g., infant formulas, follow-on formulas, dietary products for infants that are marketed as Food for Special Medical Purposes (FSMP), and other dietetic products for infants, such as complementary foods, recognizing that different criteria for nutritional and safety characterization may apply for products used as the sole or predominant food source, such as infant formulas and some FSMPs used as substitute for breast milk or formula, compared with products that comprise only a minor portion of the total dietary intake, such as complementary food. The CoN listed 13 points which, by large, were well received by the workshop participants, the exception being suggestions on setting up a central register and repository. ESPGHAN CoN suggested that manufacturers, scientific, academic, and professional groups should collaborate to the extent of agreeing to an essential portfolio of data and outcomes which will be recorded in all nutritional studies performed during early life, and to build larger databases for assessment of longterm efficacy and safety and ensure detection of unanticipated outcomes of early feeding practices and dietary exposure, and that original study records should be preserved whenever possible and used (decoded) to build a publically available archive for retrospective epidemiological assessment of outcomes.

\section{SCF Report on the Revision of Essential Requirements of Infant Formulas and Follow-On Formulas}

In this report, preceding the current directive of 2006, the committee concluded that addition of new ingredients or ingredients in amounts deviating from the established guidance on formula composition, reduction or elimination of current constituents, or any other modification should be made possible if the benefit, suitability, and safety for particular use by infants have been established by generally accepted scientific data, and this is overseen and evaluated by an independent scientific body prior to marketing such modified products. The committee further proposed some principles to be followed in the evaluation of modifications of infant formulas or followon formulas with regard to their suitability and safety for particular nutritional use by infants. Some of these principles are summarized here.

(1) Modifications beyond established standards should be based on a systematic expected benefit (nutritional, functional, technological, or other) and be based a systematic review generating a clear hypothesis on expected benefit and safety, and be the basis for decisions on further preclinical or clinical studies, including if general nutritional assessments are needed. The suitability and safety for the intended use and the extent of additional scientific data needed should be determined by an independent scientific body. 
(2) A detailed description of the modification (ingredient, composition, process used) as well as complete compositional data should be provided, particularly on those compounds that may be altered or newly formed, including possible contaminants, impurities, allergenic residues, etc. SCF guidance on safety evaluation of sources and nutrients should be followed.

(3) The mode of addition of new ingredients and description of the technological process (dry mixing or wet mixing) should be presented as well as the effect(s) on the new or existing ingredients of the process. Preclinical testing may suffice if the change is only due to a new source of a nutrient or ingredient already accepted by the EU legislation.

(4) All available biological and toxicological information should be reported (bioavailability, metabolism, biological distribution, biological effects, interactions, and toxic effects).

(5) Information on in vitro and in vivo studies in animal models should be provided if they add information on nutritional adequacy, potential benefits, and safety.

(6) If the innovation falls under the definition of a novel food, this directive [9] and the respective guidelines should be followed.

(7)If a genetically modified organism-derived ingredient or source is used, the SCF guidance on safety evaluation of genetically modified organisms should be followed.

(8)Importantly, it was emphasized that clinical trials are often needed to further characterize the suitability and safety of modifications. A trial should only be undertaken if there is reasonable assurance on the likely suitability and safety in infants based on the preclinical assessment. The gold standard for evaluation of outcomes in infants fed a modified infant formula should be comparison with outcomes seen in healthy infants who have been exclusively breastfed for 4-6 months. Clinical studies should follow the general principles of Good Clinical and Good Laboratory Practices, ethical approval should be acquired, and informed parental consent obtained. Study design should include statistical power of the study and confidence limits of any differences found included in the study reports. All infants included in clinical trials should be characterized with regard to factors which might affect the planned outcomes. A core data set should be reported for all nutritional studies in infants as proposed [10]. Blind randomization with respect to the allocation of test and reference formulas should be used whenever possible. The possibility of unexpected adverse outcomes should be anticipated and addressed by adequate clinical monitoring of participants and by incorporating into the study design arrangements for the independent scrutiny of accumulating data.

(9) For growth, comparisons should be made with either breastfed infants or infants fed a reference formula, preferentially beginning at birth and lasting for at least 3 months with at least monthly measures of length, weight, and head circumference. The study should be powered to detect a $0.5 \mathrm{SD}$ difference in weight gain. It is desirable to include some measure of body composition and also formula intake.

(10) Finally, the committee mentioned that post-market monitoring ('in-market performance review') could be useful in specific cases to monitor adverse responses to new products on the market but recognized that the execution of such a procedure needed to be preceded by structured guidelines and evaluation of an independent scientific body.

Besides infant formulas, follow-on formulas, and FSMP which are strictly regulated by directives, processed cereal-based foods and baby foods for infants and young children are also closely monitored by a directive in the EU. The legislation lays down harmonized standards for the composition (list of authorized products) and labeling of products of this type. Pesticide residues which may endanger the health of this sensitive population group are prohibited or controlled on the basis of maximum permissible quantities which may not exceed the acceptable daily intake values.

\section{Disclosure Statement}

The author has a yearly unrestricted research grant from Swedish Orphan Biovitum (Sobi) AB. The author is a member of the scientific advisory board of companies manufacturing infant formulas and baby foods.

References

1 Koletzko B, Ashwell M, Beck B, Bronner A, Mathioudakis B: Characterization of infant food modifications in the European Union. Ann Nutr Metab 2002;46:231-242.

2 Council Directive 89/398/EEC of 3 May 1989 on the approximation of the laws of the Member States relating to foodstuffs intended for particular nutritional uses. Official Journal L 186, 30/06/1989, pp 27-32. 
3 Commission of the European Communities: Commission Directive 2006/141/EC of 22 December 2006 on infant formulae and follow-on formulae, and amending directive 1999/21/EC. Official J Eur Com 2006;L 401/1:1-33.

4 European Commission, Health and Consumer Protection Directorate-General: Report of the Scientific Committee on Food on the Revision of Essential Requirements of Infant Formulae and Follow-on Formulae. SCF/CS/NUT/IF/65 Final, May 18, 2003.

5 Commission of the European Communities: Commission Directive 2006/125/EC of 5 December 2006 on processed cereal-based foods and baby foods for infants and young children. Official J Eur Com 2006;L 339/16.
6 Commission of the European Communities: Commission Directive 1999/21/EC of 25 March 1999 on dietary foods for special medical purposes. Official J Eur Com 1999;L 91/29:29-36.

7 Commission of the European Communities: White Paper on Food Safety. Brussels, Com, 1999.

$>8$ Aggett PJ, Agostini C, Goulet O, Hernell O, Koletzko B, Lafeber HL, Michaelsen KF, Rigo J, Weaver LT; European Society of Pediatric Gastroenterology, Hepatology and $\mathrm{Nu}$ trition (ESPGHAN) Committee on Nutrition: The nutritional and safety assessment of breast milk substitutes and other dietary products for infants: a commentary by the ESPGHAN Committee on Nutrition. J Pediatr Gastroenterol Nutr 2001;32:256-258.
9 Regulation (EC) No 258/97 of the European Parliament and of the Council of 27 January 1997 concerning novel foods and novel food ingredients. Official J Eur Com 1997;L 043: $1-6$.

10 Aggett $\mathrm{P}$, Agostoni C, Axelsson I, Goulet O, Hernell O, Koletzko B, Lafeber HN, Michaelsen KF, Morley R, Rigo J, Szajewska H, Weaver LT; ESPGHAN Committee on $\mathrm{Nu}$ trition: Core data for nutrition trials in infants: a discussion document - a commentary by the ESPGHAN Committee on Nutrition. J Pediatr Gastroenterol Nutr 2003;36: 338-342. 